\title{
Periampullary cyst: a surgically remediable cause of pancreatitis
}

\author{
I KALVARIA, P C BORNMAN, A H GIRDWOOD, AND I N MARKS \\ From the Gastrointestinal Clinic, Groote Schuur Hospital and the Departments of Medicine and Surgery \\ University of Cape Town, Cape Town, South Africa
}

SUMMARY We report two patients with periampullary cysts associated with recurrent attacks of acute pancreatitis. In both patients the diagnosis was made preoperatively by upper gastrointestinal endoscopy and ERCP, which was also useful in determining the relationship of the cysts to the biliary and pancreatic ductal systems. Simple marsupialisation of the cysts resulted in long term relief of symptoms. Congenital cystic anomalies in the second part of the of the duodenum should be diligently sought in patients with pancreatitis of unexplained cause, as surgical therapy is safe and effective.

With the advent of endoscopic retrograde cholangiopancreatography (ERCP), surgically remediable conditions such as biliary calculi, ampullary stenosis, and local pancreatic duct obstruction can be identified in up to two-thirds of patients with recurrent nonalcoholic pancreatitis.' ${ }^{2}$ Endoscopic retrograde cholangiopancreatography has also contributed to the recognition of an association between relapsing pancreatitis and duodenal duplication, ${ }^{3-5}$ choledochocoele,${ }^{67}$ and other rare structural anomalies. ${ }^{8} \mathrm{We}$ report two parients who presented with recurrent attacks of acute pancreatitis caused by duodenal cysts in relation to the accessory and main papilla respectively, highlighting the delay in diagnosis of these cysts, the importance of ERCP in their assessment and the long term response to appropriate surgical management.

\section{Case reports}

PATIENT 1

A 21 year old woman was investigated for recurrent pancreatitis. She had been admitted to hospital on four occasions in the preceding two years for episodes of right upper quadrant and epigastic pain radiating to the back, relieved by adopting the 'jack-knife' posture. Serum amylase was measured on two admis-

Address for correspondence: Dr I Kalvaria, Gastrointestinal Clinic, Groote Schuur Hospital. Observatory 7925. Cape Town. South Africa.

Received for publication 20 June 1986. sions and raised on both occasions ( 6100 and $4780 \mathrm{U} / \mathrm{l}$ respectively) (normal $<300 \mathrm{U} / \mathrm{l}$ ). Two ultrasonographic examinations of the upper abdomen and one barium meal had been interpreted as normal. There was no other relevant past medical history, family history or drug history and she denied alcohol intake. On examination, two weeks after her last episode of abdominal pain, the only abnormal finding was a small, non-tender, firm epigastric mass.

The serum amylase was $305 \mathrm{U} / \mathrm{l}$ and the total serum bilirubin $20 \mu \mathrm{mol} / \mathrm{l}$. The transaminase and alkaline phosphatase concentrations, the serum calcium and the plasma lipids were normal. Review of the barium meal done two years previously revealed an intraluminal filling defect in the second part of the duodenum. The lesion was cystic on computed tomographic scanning (Fig. 1). At ERCP a $4 \times 5 \mathrm{~cm}$ smooth cystic mass projected into the duodenal lumen immediately proximal to the major papilla (Fig. 2). Cholangiography was normal and pancreas divisum was demonstrated on pancreatography.

Laparotomy was carried out in view of the suspected association between the cyst adjacent to the ampulla of Vater and the history of relapsing pancreatitis. The pancreas and gall bladder were macroscopically normal but a longitudinal duodenotomy revealed a 3-4 $\mathrm{cm}$ tense cyst attached to the medial border of the second part of the duodenum just proximal to the major papilla (Fig. 3). The cyst overlay the expected site of the accessory papilla which could not be clearly identified. Aspira- 


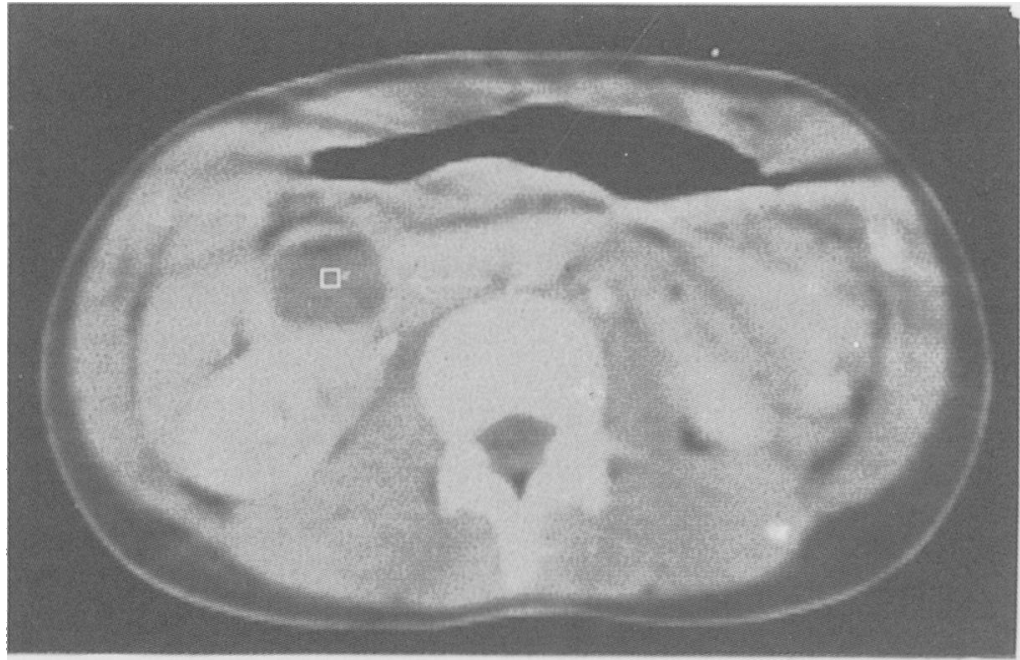

Fig. 1 Computed tomographyscan (patient 1) showing a cyst in the duodenum (marker).

tion of the cyst produced clear fluid with low amylase concentration, and contrast injection revealed no communication with the common bile duct or pancreatic duct. The cyst wall was excised except for the portion attached to the duodenal wall which was marsupialised. Postoperative recovery was uneventful. Histology of the excised wall of the cyst revealed normal duodenal mucosa on both surfaces, separated by a thin muscularis mucosa but no muscularis propria. Six months later the accessory papilla was identified at ERCP and a dorsal pancreatogram was normal. Two years after surgery the patient has experienced no further episodes of pancreatitis.

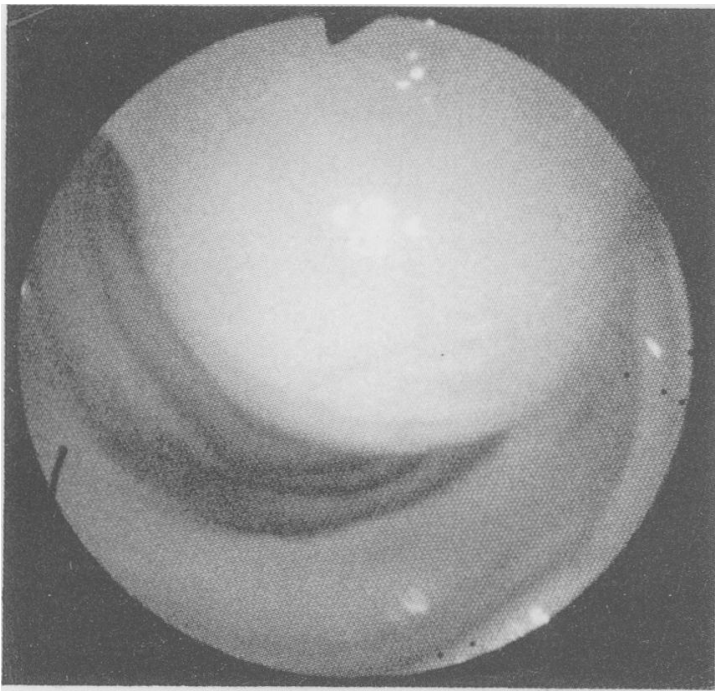

Fig. 2 Endoscopic view of second part of the duodenum at $E R C P$ (patient 1) showing a large mass protruding into the lumen.

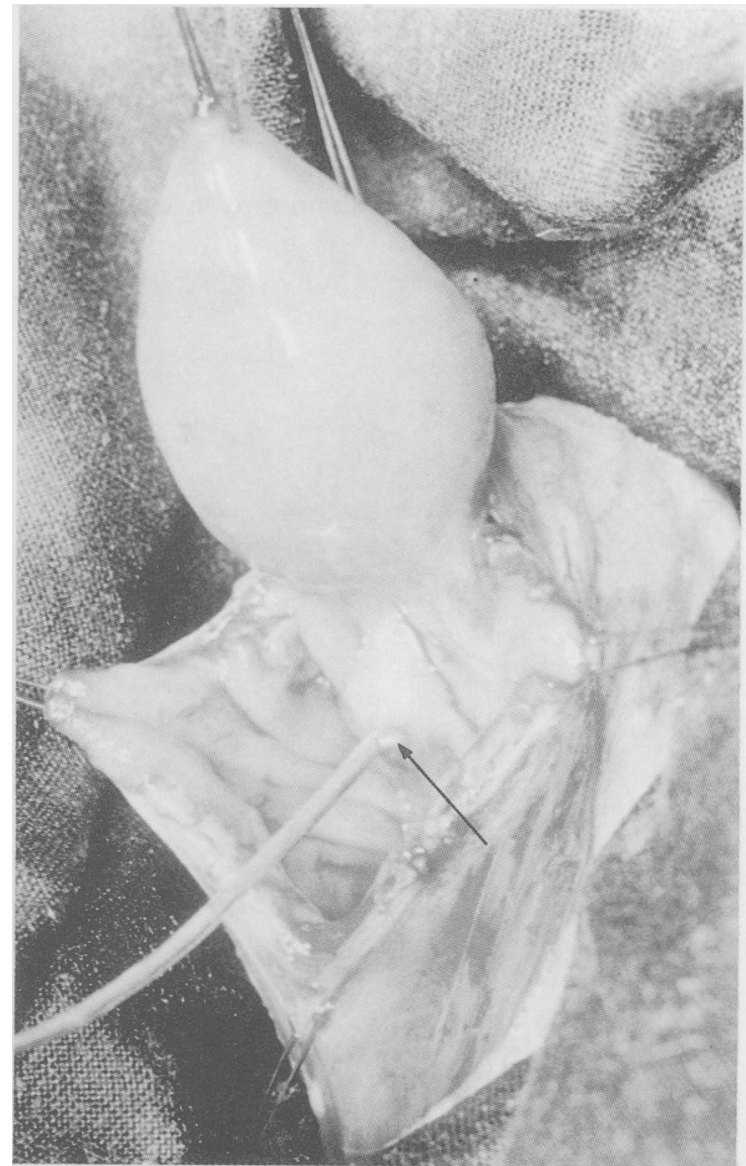

Fig. 3 Operative appearance (patient I) of cyst projecting from the medial wall of the duodenum just proximal to the cannulated major papilla (arrow). 
PATIENT 2

A 60) year old man.was admitted for investigation of recurrent abdominal pain. For 13 years he had experienced two to three episodes per year of severe epigastric pain radiating to the back, associated with jaundice on one occasion. Abdominal ultrasonography, oral cholecystography, and upper gastrointestinal barium radiology were previously normal, but endoscopy done two weeks before his admission showed a cystic swelling in the region of the ampulla of Vater. There was no relevant family history and no drug or alcohol intake. On admission he was asymptomatic and physical examination was unremarkable. The serum amylase was $821 \mathrm{U} / \mathrm{l}$, the total serum bilirubin $21 \mu \mathrm{mol} / \mathrm{l}$ and the alkaline phosphatase, serum calcium and blood lipids were normal. At ERCP a swelling was noted bulging into the lumen of the second part of the duodenum on its medial aspect. A tiny opening on the mass was cannulated and contrast injection filled a large cystic lesion which did not appear to communicate with either the biliary or pancreatic ductal systems. It was suspected, however, that the cyst occupied the ampulla of Vater, as no other structure resembling a major papilla, could be found.

At laparotomy and duodenotomy a cyst of the ampulla of Vater was identified (Fig. 4) and laid open. Both the common bile duct and pancreatic ducts opened into the floor of the cyst and were cannulated separately. The cyst was marsupialised and the patient made a good recovery. He has remained asymptomatic three years after surgery. Histology of the cyst wall was inadequate to determine its mucosal origin.

\section{Discussion}

Cystic lesions in the periampullary region may be due to a number of different causes, some of which carry a bewildering array of synonyms. These include enterogenous cyst of the duodenum, ${ }^{11 "}$ duodenal duplication, ${ }^{511 ! 2}$ juxtampullary bile filled duodenal duplication cyst, ${ }^{13}$ intraluminal duodenal diverticulum, ${ }^{1+15}$ type 111 choledochal cyst (choledochocoele), ${ }^{16}$ diverticulum of the common bile duct ${ }^{17}$ and cyst of the ampulla of Vater. ${ }^{18}$ The terminology is further complicated by the suggestion that the intraluminal duodenal diverticulum and the enterogenous or duplication cyst are varieties of the same entity. ${ }^{19}$ Similarly it has been considered that the choledochocoele represents another form of duodenal duplication, occurring at the ampulla."

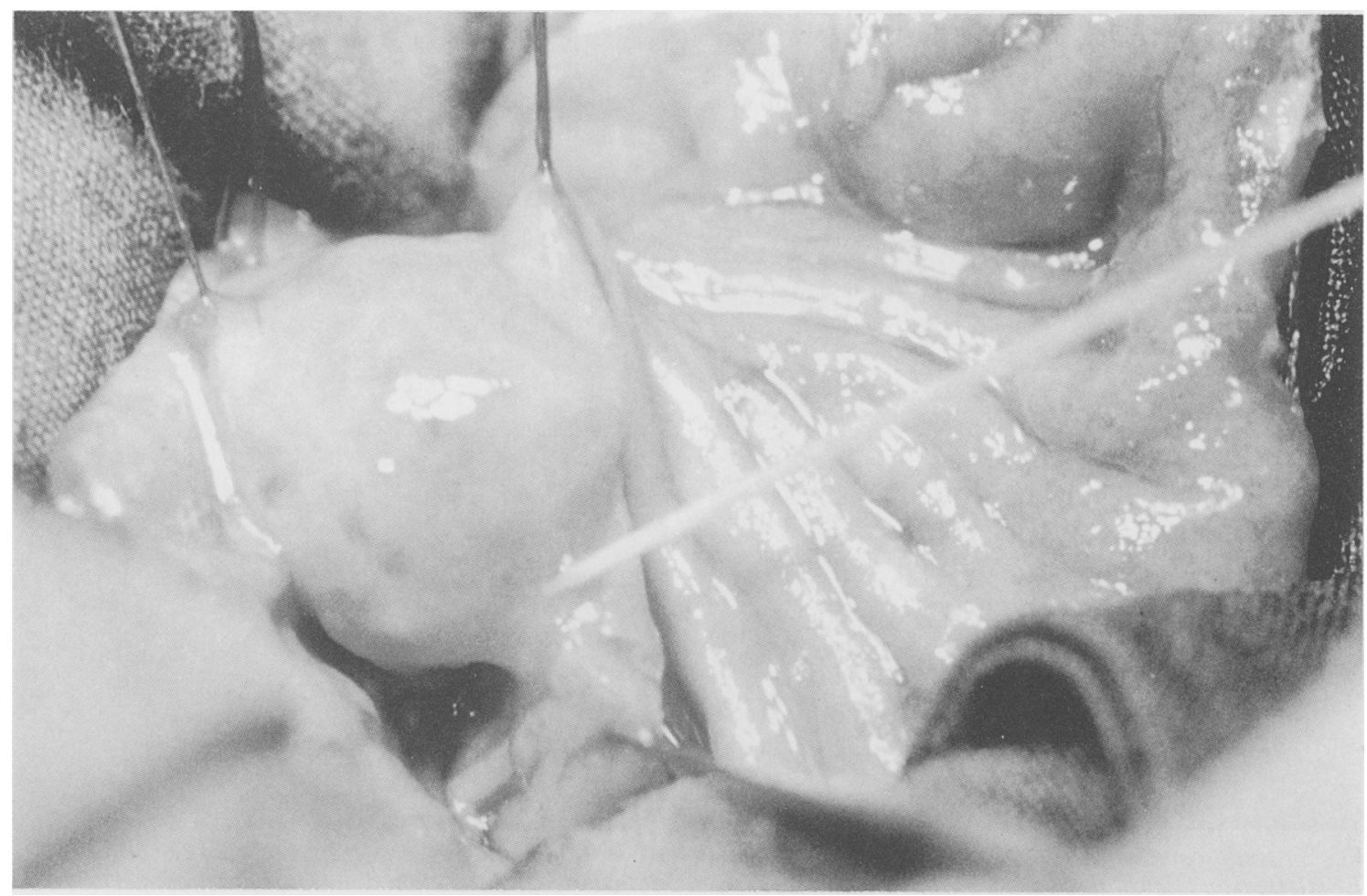

Fig. 4 Operative view (patient 2) of duodenotomy showing an ampullary cyst. 
This contention is supported by the observation that duodenal rather than biliary tract mucosa lines the majority of choledochocoeles. ${ }^{21}$

Our patients amply illustrate the difficulties encountered in placing duodenal wall cysts into precise diagnostic categories. Patient 1 does not fulfil the criteria for a duplication cyst ${ }^{22}$ in view of the absence of a circular muscle layer within the cyst wall. Furthermore the cyst did not fill with barium and cannot therefore be classified as an intraluminal duodenal diverticulum. ${ }^{23}$ A precise diagnosis is even more difficult in patient 2 whose lesion could represent a duplication cyst or diverticulum occurring at the ampulla of Vater, or even a choledochocoele. Therefore, in the absence of specific diagnostic features, we have simply termed the lesions 'periampullary cysts'.

The clinical presentation, investigation, differential diagnosis and management of duodenal wall cysts have recently been reviewed. ${ }^{3}$ Relapsing pancreatitis as exemplified by the patients in the present report, is uncommon but well described in association with duodenal duplication cyst $^{3+}$ intraluminal duodenal diverticulum ${ }^{14}$ is and choledochocoele. ${ }^{616} \mathrm{~A}$ recent review ${ }^{4}$ of eight previously reported cases of acute pancreatitis associated with duodenal duplication cysts suggests that pancreatitis results from obstruction of the ampulla of Vater caused by intermittent distension of the duplication, or to duodenal obstruction. Pancreatitis and jaundice in patient 2 of the present report may have been the consequence of an intermittent increase in pressure within the ampullary cyst resulting in ductal stasis because of obstruction or distortion.

The association of periampullary cyst with pancreas divisum (patient 1) has not previously been documented. The absence of further attacks of pancreatitis after surgical treatment of the cyst related to the accessory duct opening suggests that the latter, rather than the pancreas divisum ${ }^{24}$ was responsible for recurrent pancreatitis. Periampullary cysts are treated by surgery. In all cases a clear preoperative definition of the relationship between the cyst and the biliary and pancreatic ducts must be obtained, and is best achieved by ERCP. Although various surgical approaches have been used ${ }^{3}$ the procedure currently recommended is internal drainage of the cyst into the duodenum ${ }^{3}$ s a simple, safe, and effective operation.

Dr Kalvaria is a Boehringer Ingelheim Research Fellow in Gastroenterology. We thank the Chief Medical Superintendent, Dr H Reeve-Sanders, for permission to publish. We also gratefully acknowledge the secretarial assistance provided by Mrs Helena Essel.

\section{References}

1 Katon RM, Bilbao MK, Eidemiller LR, Benson JA Jr. Endoscopic retrograde cholangiopancreatography in the diagnosis and management of non-alcoholic pancreatitis. Surg Gynecol Obstet 1978; 147: 333-8.

2 Geenen JE, Hogan WJ. Endoscopic access to the papilla of Vater. Endoscopy 1980: suppl. 47-56.

3 Holstege A, Barner S, Brambs HJ, Wenz W, Gerok W, Farthmann EH. Relapsing pancreatitis associated with duodenal wall cysts. Diagnostic approach and treatment. Gastroenterology 1985; 88: 814-9.

4 Abrams J, Connon JJ. Duodenal duplication presenting as relapsing pancreatitis in an adult. Am J Gastroenterol 1984; 79: 360-2.

5 Luckman KF, Welch RW, Schwesinger W, Oswalt C, Bannayan G. Symptomatic duodenal duplication cyst in an adult demonstrated by endoscopic retrograde cholangiopancreatography. Am J Gastroenterol 1979; 72: 153-9.

6 Greene FL, Brown JJ, Rubinstein P, Anderson MC. Choledochocele and recurrent pancreatitis. Diagnosis and surgical management. Am J Surg 1985; 149: 306-9.

7 Venu RP, Greene JE, Hogan WJ, et al. Role of endoscopic retrograde cholangiopancreatography in the diagnosis and treatment of choledochocele. Gastroenterology 1984; 87: 1144-9.

8 Hatfield ARW, Dent DM, Marks IN. An intrapapillary pancreatic duct diverticulum: a rare but surgically correctable cause of juvenile pancreatitis. Br J Surg 1982; 69: 430-1.

9 Kirtley JA Jr, Matuska RA. Enterogenous cyst of the duodenum. Ann Surg 1957; 145: 265-8.

10 Ortiz VM, Nealon TF, Mitty WF. Enterogenous cyst of the duodenum. Am J Gastroenterol 1974; 61: 276-81.

11 Basu R, Forshall I, Rickham PP. Duplications of the alimentary tract. Br J Surg 1960; 47: 477-84.

12 Browning RW. Duodenal duplications. Rev Surg 1963; 20: $226-9$.

13 Jones PA, Rayter Z, Knight MJ, Rosswick RPR. Juxtampullary, bile-filled duodenal duplication cyst: another surgically correctable cause of acute pancreatitis. JR Soc Med 1982; 75: 662-4.

14 Nosher JL, Seaman WB. Association of intraluminal duodenal diverticulum with acute pancreatitis. Radiology 1975; 115: 21-2.

15 Griffin M, Carey WD, Hermann R, Buonocore E. Recurrent acute pancreatitis and intussusception complicating an intraluminal duodenal diverticulum. Gastroenterology 1981; 81: 345-8.

16 Wheeler WI DeC. An unusual case of obstruction to the common bile-duct (choledochocele ?). Br J Surg 1940; 27: 446-8.

17 Alden JF, Sterner ER. Diverticulum of the common bile duct: a case report. Ann Surg 1957; 145: 269-70.

18 Brooks B, Weinstein A. Cyst of the ampulla of Vater. Ann Surg 1943; 117: 728-34.

19 Wiot JF, Spiro E. Intraluminal diverticulum: a form of duplication. Radiology 1963; 80: 46-9. 
20 Reinus FZ, Weingarten G. Choledochocele of the common bile duct. Am J Surg 1976; 132: 646-8.

21 Alonso-Lej F, Rever WB Jr, Pessagno DJ. Congenital choledochal cyst, with a report of 2 , and an analysis of 94, cases. Int Abstr Surg 1959; 108: 1-30.

22 Trier JS, Krone CL, Sleisenger MH. Anatomy, embryology and developmental abnormalities of the small intestine and colon. In: Sleisenger MH, Fordtran JS, eds. Gastrointestinal disease: pathophysiology, diagno- sis, management. Philadelphia: Saunders, 1983: 780-811.

23 Perrin RW. Communicating enterogenous cyst of the duodenum receiving the termination of the common bile duct demonstrated by intravenous cholangiography. Radiology 1969; 93: 675-6.

24 Cotton PB. Congenital anomaly of pancreas divisum as cause of obstructive pain and pancreatitis. Gut 1980: 21: 105-14. 